\title{
Fragmented mitochondrial genomes of the rat lice, Polyplax asiatica and Polyplax spinulosa: intra-genus variation in fragmentation pattern and a possible link between the extent of fragmentation and the length of life cycle
}

\author{
Wen-Ge Dong ${ }^{1,2}$, Simon Song ${ }^{3}$, Dao-Chao Jin ${ }^{1 *}$, Xian-Guo Guo ${ }^{2}$ and Renfu Shao ${ }^{3}$
}

\begin{abstract}
Background: Blood-sucking lice (suborder Anoplura) parasitize eutherian mammals with $67 \%$ of the 540 described species found on rodents. The five species of blood-sucking lice that infest humans and pigs have fragmented mitochondrial genomes and differ substantially in the extent of fragmentation. To understand whether, or not, any life-history factors are linked to such variation, we sequenced the mt genomes of Polyplax asiatica and Polyplax spinulosa, collected from the greater bandicoot rat, Bandicota indica, and the Asian house rat, Rattus tanezumi, respectively.

Results: We identified all of the 37 mitochondrial genes common to animals in Polyplax asiatica and Polyplax spinulosa. The mitochondrial genes of these two rat lice are on 11 circular minichromosomes; each minichromosome is $2-4 \mathrm{~kb}$ long and has 2-7 genes. The two rat lice share the same pattern for the distribution of the protein-coding genes and ribosomal RNA genes over the minichromosomes, but differ in the pattern for the distribution of 8 of the 22 transfer RNA genes. The mitochondrial genomes of the Polyplax rat lice have 3.4 genes, on average, on each minichromosome and, thus, are less fragmented than those of the human lice (2.1 and 2.4 genes per minichromosome), but are more fragmented than those of the pig lice (4.1 genes per minichromosome).

Conclusions: Our results revealed distinct patterns of mitochondrial genome fragmentation within the genus Polyplax and, furthermore, indicated a possible inverse link between the extent of mitochondrial genome fragmentation and the length of life cycle of the blood-sucking lice.
\end{abstract}

Keywords: Mitochondrial genome, Genome fragmentation, Minichromosome, Chromosome evolution, Sucking lice

\section{Background}

Lice in the suborder Anoplura are wingless, exclusive blood-sucking insects and are permanent ectoparasites of eutherian mammals [1,2]. Blood-sucking lice evolved from chewing lice $\sim 100$ million years ago (Mya) and diversified rapidly $\sim 65$ Mya with their mammalian hosts [3]. More than 540 species of blood-sucking lice have been described and are classified into 15 families

\footnotetext{
* Correspondence: daochaojin@126.com

'Institute of Entomology, Guizhou University, and the Provincial Key Laboratory for Agricultural Pest Management in Mountainous Region, Guiyang 550025, China

Full list of author information is available at the end of the article
}

and 50 genera [4-7]. Twelve of the 29 recognized mammalian orders and 240 mammalian species are hosts of blood-sucking lice. The diversity of blood-sucking lice mirrors that of their mammalian hosts with $67 \%$ of the described species found on rodents [2,5,7]. Each species of mammalian host is usually parasitized by a single species of blood-sucking lice, but there are exceptions as many mammalian species are hosts of multiple species of blood-sucking lice (up to seven species) [7]. Vice versa, each species of blood-sucking lice usually parasitizes only one species of mammals, but many species of blood-sucking lice parasitize multiple 
species of mammals that are closely related phylogenetically (up to 39 species) [6].

Adding to their unique, exclusive blood-feeding life style and the high host-specificity (relative to other ectoparasites), recent studies revealed that blood-sucking lice have an unusual, fragmented mitochondrial (mt) genome organization. For insects and other bilateral animals, the mt genome is usually a single, circular chromosome, 13-20 kb long, with 37 genes: 13 for proteins, two for ribosomal RNAs and 22 for transfer RNAs [8,9]. The mt genomes of the human body louse, Pediculus humanus, and the human head louse, Pediculus capitis, however, have 20 minichromosomes; each minichromosome has $1-3$ genes and is $3-4 \mathrm{~kb}$ in size $[10,11]$. The $34 \mathrm{mt}$ genes identified in the human pubic louse, Pthirus pubis, are on 14 minichromosomes; each minichromosome has $1-5$ genes and is $1.8-2.7 \mathrm{~kb}$ in size $[10,11]$. The domestic pig louse, Haematopinus suis, and the wild pig louse, Haematopinus apri, have their $37 \mathrm{mt}$ genes on nine minichromosomes; each minichromosome has $2-8$ genes and is $3-4 \mathrm{~kb}$ in size [12].

The fragmented mitochondrial genomes of the human lice and the pig lice represent the most radical departure to date in bilateral animals from the typical, single-chromosome organization of $\mathrm{mt}$ genomes, although multipartite $\mathrm{mt}$ genomes have also been observed in the rotifer, Brachionus plicatilis, and the booklouse, Liposcelis bostrychophila, which have two mt chromosomes [13,14], and the potato cyst nematode, Globodera pallida, which has six chromosomes [15]. Outside bilateral animals, highly fragmented mt genomes were observed in ichthyosporean protists [16], diplonemid protists [17] and box jellyfish [18].

Although all having fragmented mt genomes, the human lice and the pig lice differ substantially in the extent of mt genome fragmentation and in the distribution of mt genes over the minichromosomes [12]. To understand whether, or not, any life-history factors are linked to such variation, we sequenced the mt genomes of two species of blood-sucking lice that parasitize rats, Polyplax asiatica (Ferris 1923) and Polyplax spinulosa (Burmeister 1839). Polyplax is one of the most species-rich genus of the suborder Anoplura with 78 described species, second only to the genus Hoplopleura, which has 141 described species [6]. Polyplax species shared their most recent common ancestor (MRCA) with primate lice $~ 47$ Mya and their MRCA with pig lice $\sim 67$ Mya [3]. Po. asiatica infests the greater bandicoot rat, Bandicota indica, three other related species of rats and occasionally the Asian house shrew, Suncus murinus [7,19]. Po. spinulosa infests the Asian house rat, Rattus tanezumi, the brown rat, Rattus norvegicus, the black rat, Rattus rattus, and six other related species of rats [6,7]. While Po. asiatica is only found in Asia, Po. spinulosa has a worldwide distribution and is responsible, as a vector, for the transmission of pathogenic microorganisms such as Mycoplasma haemomuris (formerly known as Haemobartonella muris), Rickettsia typhi, Trypanosoma lewisi, Borrellia duttoni and Brucella brucei [20-22]. We show that both Po. asiatica and Po. spinulosa have fragmented $\mathrm{mt}$ genomes; these two species, however, differ in the pattern of $\mathrm{mt}$ genome fragmentation. Furthermore, our comparison among the rat lice, the human lice and the pig lice indicates a possible inverse link between the extent of $\mathrm{mt}$ genome fragmentation and the length of life cycle of these lice.

\section{Methods}

\section{Collection of rats and lice}

The blood-sucking lice, Po. asiatica and Po. spinulosa, were collected in 2011 from the greater bandicoot rat, $B$. indica, and the Asian house rat, R. tanezumi, respectively, in Jinping county, Yunnan province, China. The rats were caught with trap-cages set indoors (farmers' houses, barns and stables) and outdoors (farmlands, scrublands and woodlands). Alive rats trapped were placed individually in pre-marked cotton bags and transferred to laboratory for species identification and parasitological check. Blood-sucking lice on the body surface of each rodent host were collected and preserved in 95\% ethanol at $-20^{\circ} \mathrm{C}$ prior to DNA extraction. Samples of Po. asiatica and Po. spinulosa and their rat hosts were deposited in the Institute of Pathogens and Vectors, Dali University. The capture of rodents was approved by health authorities in Yunnan province, China. Animal protocols and procedures were approved by the animal ethics committees at Guizhou University and Dali University.

\section{DNA extraction, mitochondrial genome amplification and sequencing}

Genomic DNA was extracted from individual louse specimens with DNeasy Tissue kit (QIAGEN). For Po. asiatica (sample \#57) collected from the greater bandicoot rats, a 532-bp fragment of cox 1 and a 360-bp fragment of $r r n L$ were initially amplified by PCR with primer pairs mtd6-mtd9 and16SF-Lx16SR (see Additional file 1). These two pairs of primers target conserved sequence motifs in cox 1 and $r r n L$; the amplicons were sequenced directly using Sanger method at the Tiangen Biotech, Beijing (TBB). Two pairs of specific primers for Po. asiatica, cox57F-cox57R and 16S57F-16S57R, were designed from sequences of the cox 1 and $r r n L$ fragments. The two specific primers in each pair go outbound with $131 \mathrm{bp}$ and $1 \mathrm{bp}$, respectively, in between. PCRs with these specific primers amplified two near full-length mt minichromosomes of Po. asiatica that contain cox 1 and $r r n L$ respectively; these amplicons $(3.2 \mathrm{~kb}$ and $2.6 \mathrm{~kb}$ in size) were sequenced using Sanger method at the TBB. Another pair of primers specific to Po. asiatica, 57F-57R, was designed from conserved non-coding sequences that flank the coding regions of the two 
minichromosomes above. The PCR with 57F-57R primer pair produced a mixture of amplicons ranging from 1 to $2 \mathrm{~kb}$ in size, expected from the coding regions of all $\mathrm{mt}$ minichromosomes of Po. asiatica (Figure 1A). These amplicons were sequenced with Illumina Hiseq 2000 platform at the Beijing Genome Institute, Hong Kong (BGI-HK). The PCR strategy used in this study was developed from the observations we made in previous studies on the human lice and the pig lice that each $\mathrm{mt}$ minichromosome has a distinct coding region but a well-conserved non-coding region [10-12].

For Po. spinulosa (sample \#301) collected from the Asian house rats, a 452-bp fragment of $r r n S$ and a 360-bp fragment of $r r n L$ were amplified initially by PCR with primer pairs 12SA-12SB and 16SF-Lx16SR (see Additional file 1). These two pairs of primers target conserved sequence motifs in $r r n S$ and $r r n L$ and the PCR amplicons were sequenced directly using Sanger method at the TBB. Two pairs of specific primers for Po. spinulosa, 12S301F-12S301R and 16S301F-16S301R, were designed from sequences of the $r r n S$ and $r r n L$ fragments. The two specific primers in each pair go outbound and are $1 \mathrm{bp}$ and $89 \mathrm{bp}$ respectively from each other. PCRs with these two pairs of specific primers amplified two $\mathrm{mt}$ minichromosomes of Po. spinulosa that contain $r r n S$ and $r r n L$ respectively; these amplicons ( $2 \mathrm{~kb}$ and $2.3 \mathrm{~kb}$ in size) were sequenced using Sanger method at the TBB. Another pair of primers specific to Po. spinulosa, 301F-301R, was designed from conserved non-coding sequences that flank the coding regions of the two minichromosomes above. The PCR with primer pair 301F-301R produced a mixture of amplicons ranging from 1 to $2 \mathrm{~kb}$ in size, expected from the coding regions of all $\mathrm{mt}$ minichromosomes of $\mathrm{Po}$. spinulosa (Figure 1A). These amplicons were sequenced with Illumina Hiseq 2000 platform at the BGI-HK.
Taq DNA Polymerase (Tiangen Biotech) was used in the initial short PCRs with the following cycling conditions: $94^{\circ} \mathrm{C}$ for $1 \mathrm{~min}$; 35 cycles of $98^{\circ} \mathrm{C}$ for $10 \mathrm{sec}, 45^{\circ} \mathrm{C}$ for $30 \mathrm{sec}, 72^{\circ} \mathrm{C}$ for $1 \mathrm{~min}$; and a final extension of $72^{\circ} \mathrm{C}$ for 2 min. LA Taq (TaKaRa) was used in the long PCRs with the cycling conditions: $94^{\circ} \mathrm{C}$ for $1 \mathrm{~min}, 35$ cycles of $98^{\circ} \mathrm{C}$ for $10 \mathrm{sec}, 60-65^{\circ} \mathrm{C}$ (depending on primers) for $30-40 \mathrm{sec}$, $68^{\circ} \mathrm{C}$ for $3 \mathrm{~min}$; and $72^{\circ} \mathrm{C}$ for $6 \mathrm{~min}$. Positive and negative controls were executed with each PCR. PCR amplicons were checked by agarose gel (1\%) electrophoresis; the sizes of PCR amplicons were estimated by comparing with molecular markers. PCR products were purified with Wizard SV Gel and PCR clean-up system (Promega).

\section{Assembly of Illumina sequence-reads, gene identification and verification of individual mitochondrial minichromosomes}

Illumina sequence-reads obtained from the $\mathrm{mt}$ minichromosomes of Po. asiatica and Po. spinulosa were assembled into contigs with Geneious 6.1.6 [23]; the parameters for assembly were minimum overlap identity $98 \%$ and minimum overlap $50 \mathrm{bp}$. tRNA genes were identified using tRNAscan-SE [24] and ARWEN [25]. Protein-coding genes and rRNA genes were identified with BLAST searches of GenBank [26,27]. Identical sequences shared between genes were identified with Wordmatch [28]. Sequence alignments were with Clustal X [29]. The size and circular organization of each mt minichromosome of Po. asiatica and Po. spinulosa identified by sequence-read assembly were verified by PCR (Figure 1B, 1C). A pair of outbound primers (forward and reverse) was designed from the coding region of each minichromosome (see Additional file 2). The two primers in each pair were next to each other with a small gap or no gap in between. PCRs with these primers amplify the full or near

\section{(A)}

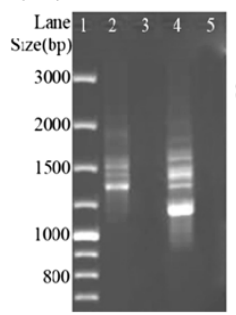

(B)

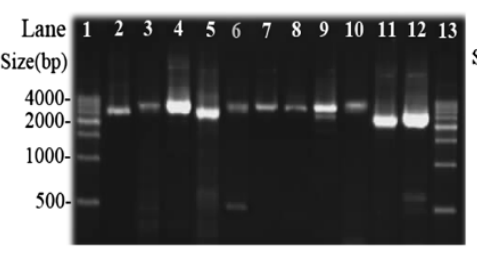

(C)

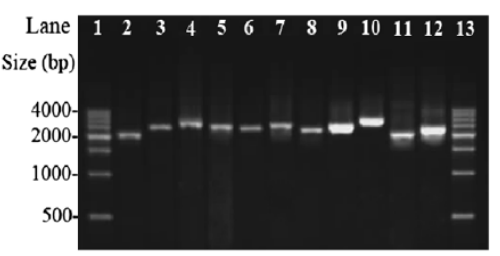

Figure 1 PCR amplification of the mitochondrial (mt) minichromosomes of the Polyplax rat lice. (A) Lane 1: GeneRuler ${ }^{\circledR} 100$ bp DNA Ladder (Thermo Scientific). Lane 2: PCR amplicons generated with primer pair 57F-57R that spans the coding region of each mitochondrial (mt) minichromosome of Polyplax asiatica. Lane 4: PCR amplicons generated with primer pair 301F-301R that spans the coding region of each mt minichromosome of Polyplax spinulosa. (B) PCR verification of the mt minichromosomes of Po. asiatica. Lane 1 and 13: 500 bp DNA Ladder (TIANGEN). Lane 2-12: PCR amplicons from the 11 minichromosomes of Po. asiatica: atp8-atp6, trnE-cob-trnl, cox1-trnL (taa), trnD-trnY-cox2-nad6, $\operatorname{trnR}$-nad4L-cox3-trnA, $\boldsymbol{t r n S}_{\mathbf{1}}(\boldsymbol{t c t})$-trnS $\mathbf{S}_{2}(\operatorname{tga})$-nad1-trnT-trnG-nad3-trnW, trnQ-nad2-trnN-trnP, trnK-nad4-trnF, trnH-nad5, rrnS-trnC, trnM-trnL (tag)-rrnL-trnV. (C) PCR verification of the mt minichromosomes of Po. spinulosa. Lane 1 and 13: 500 bp DNA Ladder (TIANGEN). Lane 2-12: PCR amplicons from the 11

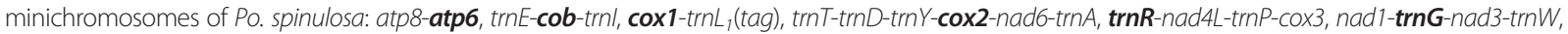
trnQ-nad2-trnN, trnK-nad4, trnH-nad5-trnF, trnS 1 (tct)-trnS ${ }_{2}$ (tga)-rrnS-trnC, trnM-trnL ${ }_{2}(t a a)$-rrnL-trnV. Genes from which PCR primers were designed are in bold. 
full length of each minichromosome if it has a circular organization. PCR set-up, cycling conditions, agarose gel electrophoresis and size measurement were the same as described above. The nucleotide sequences of the $\mathrm{mt}$ genomes of Po. asiatica and Po. spinulosa have been deposited in GenBank under accession numbers KF647751KF647772.

\section{Results}

Mitochondrial genome of Polyplax asiatica, the louse of the greater bandicoot rats

We obtained 546,066 sequence-reads from the $\mathrm{mt}$ genome of Po. asiatica by Illumina sequencing (Table 1). The sequence-reads are $90 \mathrm{bp}$ each; assembly of these sequence-reads into contigs allowed us to identify all of the $37 \mathrm{mt}$ genes typical of animals in Po. asiatica distributed over 11 minichromosomes (Figure 2A; Table 1). Each minichromosome is circular, $2.4-3.3 \mathrm{~kb}$ in size (Figure 1B), and consists of a coding region and a non-coding region. Each coding region contains two to seven genes, and varies in size from $802 \mathrm{bp}$ for $\mathrm{rrnS}$-trnC minichromosome to 1,756 bp for trnH-nad5 minichromosome (Table 1; Figure 2A) (Note: minichromosomes are named after their genes hereafter). Seven of the 11 minichromosomes of Po. asiatica have one protein-coding or rRNA gene each; the other four minichromosomes have two proteincoding genes each. The 22 tRNA genes are scattered over 10 of the 11 minichromosomes; each minichromosome has one to five tRNA genes except atp8-atp6, which has no tRNA genes (Figure 2A). Each of the $37 \mathrm{mt}$ genes identified in Po. asiatica is present on only one minichromosome; there is no overlap in gene content

\begin{tabular}{|c|c|c|}
\hline Minichromosome & $\begin{array}{l}\text { Size of coding } \\
\text { region (bp) }\end{array}$ & $\begin{array}{c}\text { Number of Illumina } \\
\text { sequence-reads }\end{array}$ \\
\hline atp8-atp6 (atp8-atp6) & 838 (832) & $73276(143560)$ \\
\hline$E-c o b-I(E-c o b-l)$ & $1242(1228)$ & $47008(50108)$ \\
\hline $\cos 1-L_{2}\left(\cos 1-L_{1}\right)$ & $1626(1599)$ & $49653(49675)$ \\
\hline D-Y-cox2-nad6 (T-D-Y-cox2-nad6-A) & $1292(1399)$ & $35911(41691)$ \\
\hline R-nad4L-cox3-A (R-nad4L-P-cox3) & $1268(1190)$ & $36763(64203)$ \\
\hline $\begin{array}{l}S_{1}-S_{2}-\text { nad1-T-G-nad3-W } \\
\text { (nad1-G-nad3-W) }\end{array}$ & $1602(1419)$ & $21705(66380)$ \\
\hline Q-nad2-N-P (Q-nad2-N) & $1385(1134)$ & $24989(46412)$ \\
\hline K-nad4-F (trnK-nad4) & $1465(1331)$ & 38589 (78061) \\
\hline H-nad5 (trnH-nad5-trnF) & $1756(1816)$ & $39554(44417)$ \\
\hline$r r n S-C\left(S_{1}-S_{2}-r r n S-C\right)$ & $802(904)$ & $121142(165740)$ \\
\hline$M-L_{1}-r r n L-V\left(M-L_{2}-r r n L-V\right)$ & $1333(1237)$ & $57476(96783)$ \\
\hline Total & 14609 (14089) & $546066(847030)$ \\
\hline
\end{tabular}

Note: Gene arrangements and numbers outside brackets are for Polyplax asiatica and those in brackets are for Polyplax spinulosa. between different minichromosomes. All of the $37 \mathrm{mt}$ genes have the same orientation of transcription relative to the non-coding region, except $\operatorname{trn} T$ and nad1, which have the opposite orientation of transcription relative to other genes (Figure 2A).

We sequenced the full-length non-coding regions, $1,532 \mathrm{bp}$ and 1,244 bp respectively, of two mt minichromosomes of Po. asiatica: cox1-trnL $L_{2}$ and $\operatorname{trnM} M-\operatorname{trn} L_{1}-r r n L-\operatorname{trn} V$. The length variation between the two non-coding regions is due to a 304-bp section that is present only in cox1-trn $L_{2}$ minichromosome lying downstream the coding region and a 25-bp section that is present only in $\operatorname{trnM-\operatorname {trn}L_{1}-rrnL-}$ trn $V$ minichromosome lying upstream the coding region (Figure 3A). Excluding these two sections, the non-coding regions of the two minichromosomes have $96 \%$ identity to each other. As in the human lice and the pig lice [11,12], an AT-rich motif (140 bp, $64 \% \mathrm{~A}$ and $\mathrm{T}$ ) is present in the non-coding regions of Po. asiatica upstream the 5'-end of the coding region, whereas a GC-rich motif (76 bp, 71\% G and $\mathrm{C}$ ) is present downstream the 3 '-end of the coding region (Figure $3 \mathrm{~A}$ ). In addition to the full-length non-coding region sequences of the two minichromosomes, we also obtained partial sequences of the non-coding regions, 101-169 bp and 49-449 bp respectively, upstream and downstream the coding regions of the other nine minichromosomes of Po. asiatica. Two highly conserved sequence-motifs, $101 \mathrm{bp}$ and $44 \mathrm{bp}$ long respectively, are present in the sections of the non-coding regions upstream and downstream the coding regions of all of the 11 minichromosomes (see Additional file 3).

\section{Mitochondrial genome of Polyplax spinulosa, the louse of the Asian house rats}

We obtained 847,030 sequence-reads from the $\mathrm{mt}$ genome of Po. spinulosa by Illumina sequencing (Table 1). As above for Po. asiatica, these sequence-reads are 90 bp each in length. We assembled these sequence-reads into contigs and identified all of the $37 \mathrm{mt}$ genes typical of animals in Po. spinulosa. These genes are on 11 minichromosomes; each minichromosome is $2.0-2.9 \mathrm{~kb}$ in size and has a circular organization (Figure 1C; Figure 2B). As in Po. asiatica, seven of the 11 minichromosomes of Po. spinulosa have one protein- or rRNA-coding gene each; the other four minichromosomes have two protein-coding genes each. The 22 tRNA genes are on 10 of the 11 minichromosomes; each minichromosome has one to four tRNA genes except atp8-atp6, which has no tRNA genes (Figure 2B). Each minichromosome has a coding region and a non-coding region. The coding region of each minichromosome contains two to six genes, and varies in size from $832 \mathrm{bp}$ for atp8atp6 minichromosome to 1,816 bp for trnH-nad5-trnF minichromosome. With the only exception of nad1, all of the mt genes of Po. spinulosa have the same orientation of transcription relative to the non-coding regions (Figure 2B). 


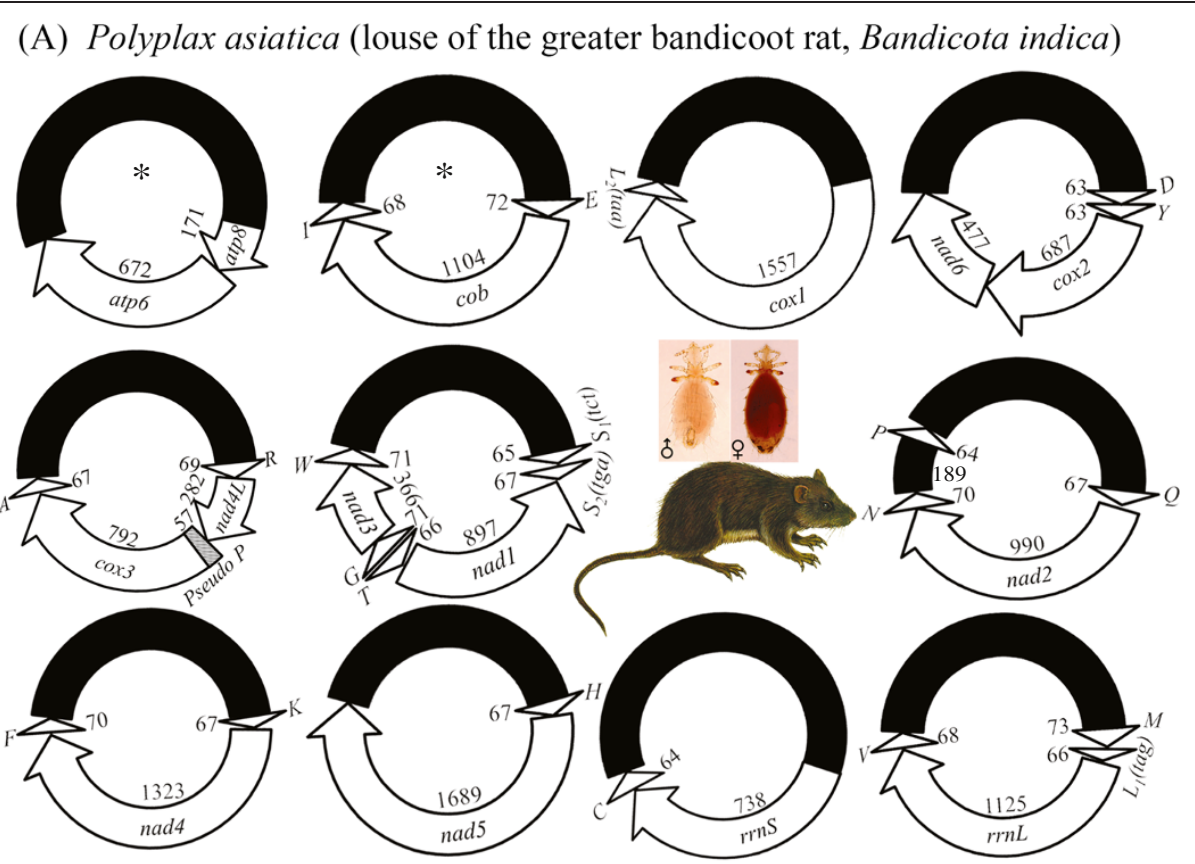

(B) Polyplax spinulosa (louse of the Asian house rat, Rattus tanezumi)
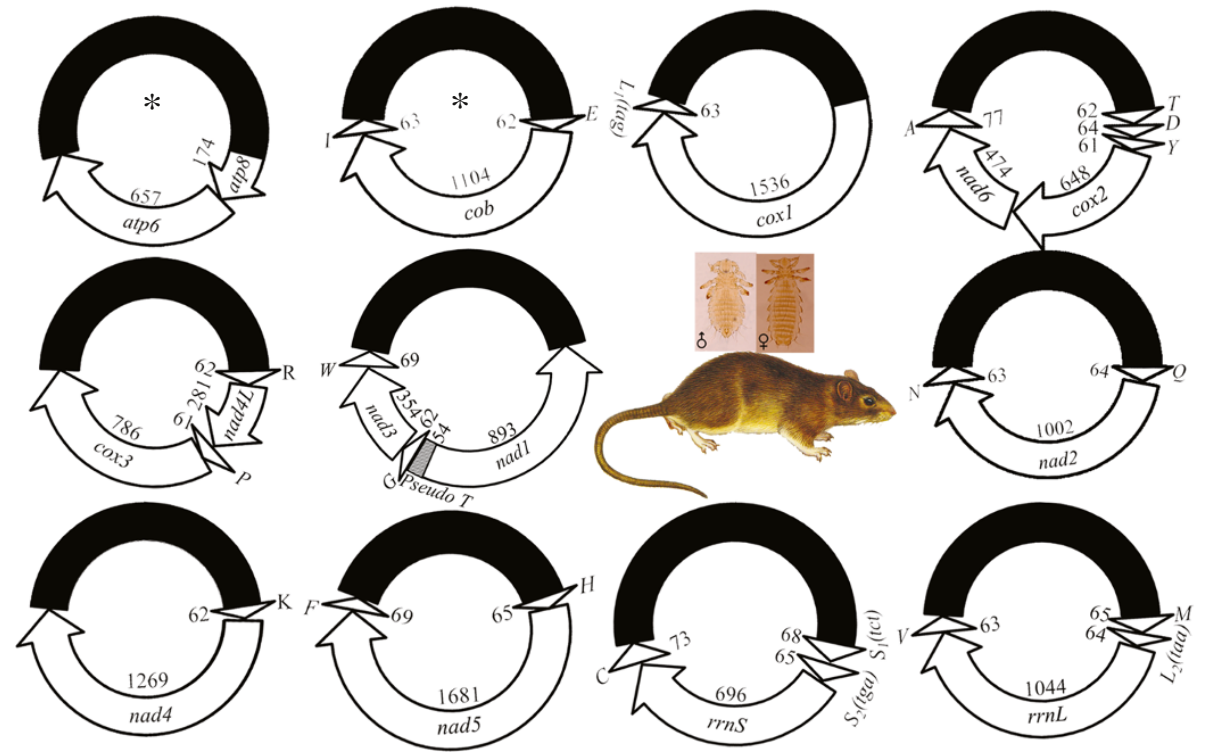

Figure 2 The mitochondrial (mt) genomes of Polyplax asiatica (A) and Polyplax spinulosa (B). Each minichromosome has a coding region (with gene name, transcription orientation and length indicated) and a non-coding region (in black). Minichromosomes are in alphabetical order by the names of their protein coding and rRNA genes. Abbreviations of gene names are: atp6 and atp8 (for ATP synthase subunits 6 and 8), cox 1-3 (for cytochrome c oxidase subunits 1-3), cob (for cytochrome b), nad1-4 and nad4L (for NADH dehydrogenase subunits 1-6 and 4 L), rrnS and $r$ rnL (for small and large subunits of ribosomal RNA). tRNA genes are shown with the single-letter abbreviations of their corresponding amino acids. Minichromosomes that have identical gene content and gene arrangement between the two Polyplax species are indicated with asterisk symbols "*".

We sequenced the full-length non-coding regions, $1,097 \mathrm{bp}$ and 1,146 bp respectively, of two mt minichromosomes of Po. spinulosa: trnM-trn $L_{2}-r r n L-\operatorname{trn} V$ and $t r n S_{1}-t r n S_{2}-r r n S-t r n C$. The length variation between the two non-coding regions is due to a 53-bp section that is present only in $\operatorname{trnS}_{1}$-trnS $S_{2}$-rrnS-trnC minichromosome lying upstream the coding region (Figure 3B). Excluding the 53-bp section, the non-coding regions of the two minichromosomes have $98 \%$ identity to each other. As above in Po. asiatica, an AT-rich motif (192 bp, $64 \% \mathrm{~A}$ and $\mathrm{T}$ ) is present in the non-coding regions in Po. spinulosa upstream the 5'-end of the coding 


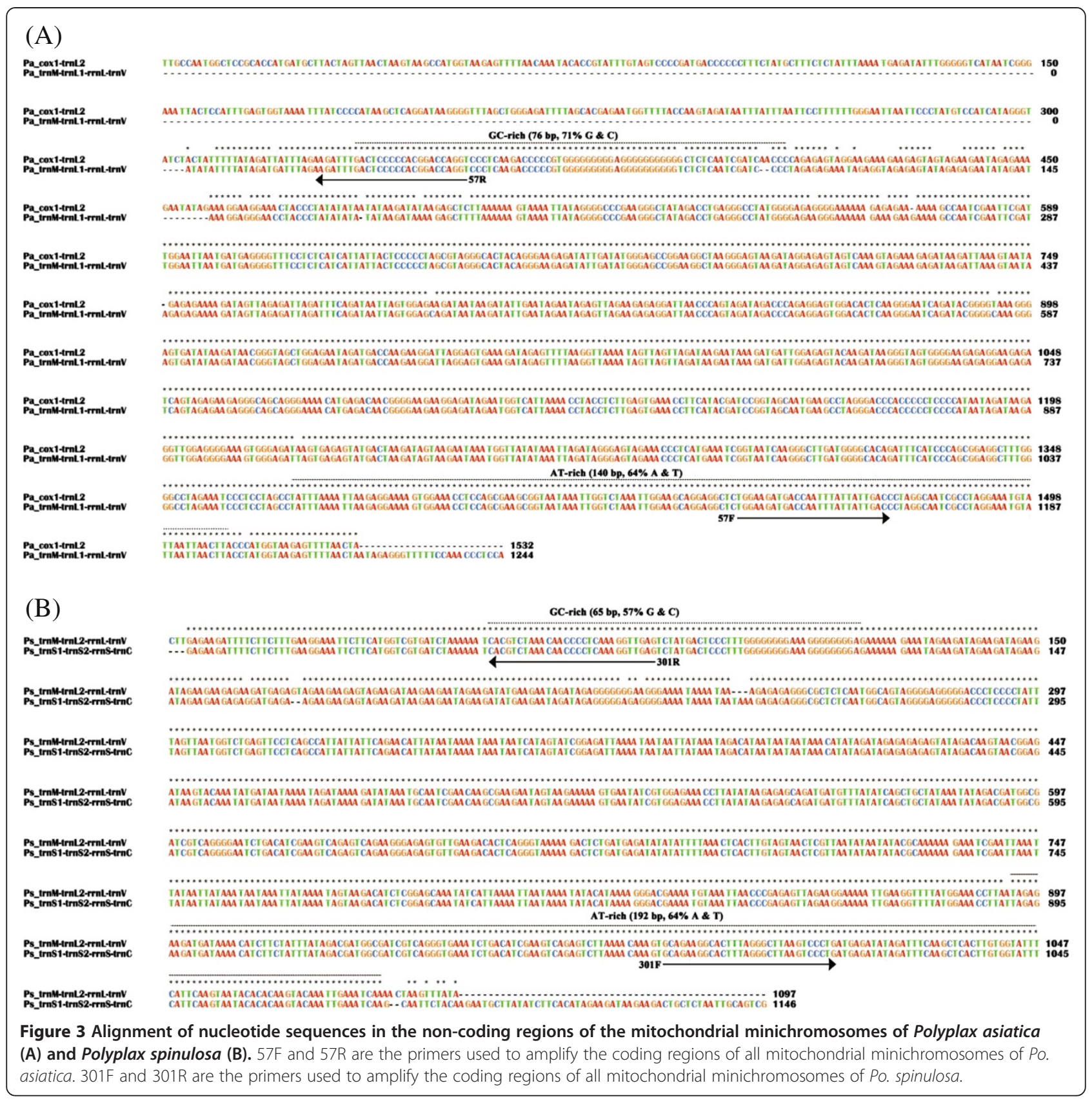

region, and a GC-rich motif (65 bp, 57\% G and C) is present downstream the 3 '-end of the coding region (Figure 3B). Additional to the full-length non-coding region sequences of the two minichromosomes, we also obtained partial sequences of the non-coding regions, 95-217 bp and 74-136 bp respectively, upstream and downstream the coding regions of the other nine minichromosomes of Po. spinulosa. As in Po. asiatica, two highly conserved sequence-motifs, $95 \mathrm{bp}$ and 74 bp long respectively, are present in the sections of the non-coding regions upstream and downstream the coding regions of all of the 11 minichromosomes (see Additional file 4).

\section{Discussion}

Variation in the pattern of $\mathrm{mt}$ genome fragmentation between the two Polyplax rat lice

Only two of the 11 minichromosomes have identical gene content and gene arrangement between Po. asiatica and Po. spinulosa, revealing, for the first time, marked intra-genus variation in the pattern of $\mathrm{mt}$ genome fragmentation among blood-sucking lice (Figure 2). Comparison between the two Polyplax rat lice, and with the pig lice and the human lice, revealed the translocations of tRNA genes between minichromosomes in both Po. asiatica and Po. spinulosa after these two species split from their MRCA, and furthermore, 


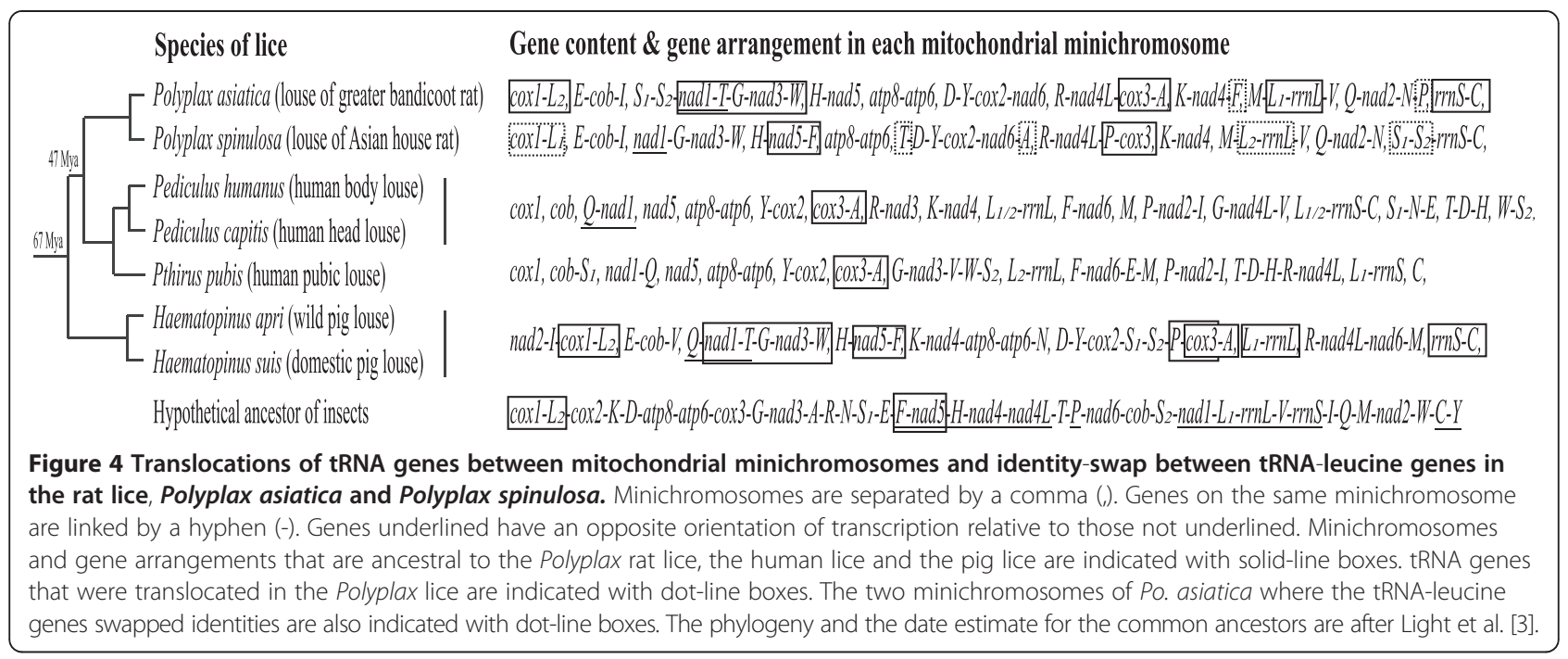

the swap of identities between the two tRNA-leucine genes in Po. spinulosa after the split.

RrnS-trnC minichromosome is present in the rat louse, Po. asiatica, and the two Haematopinus species of the pig lice, indicating this minichromosome is ancestral to the rat lice, the pig lice and the human lice (Figure 4). In the rat louse, Po. spinulosa, however, $\operatorname{trn} S_{1}$-trn $S_{2}$ has been inserted upstream rrnS gene (Figure 2B; Figure 4). The gene arrangement, nad1-trnT-trnG-nad3-trnW (genes in bold have opposite orientation of transcription to others), is present in Po. asiatica and the Haematopinus pig lice, indicating this arrangement to be ancestral to the rat lice, the pig lice and the human lice (Figure 4). In Po. spinulosa, however, $\operatorname{trn} T$ has been inserted upstream $\operatorname{trn} D$ gene, leaving a 54-bp pseudo-trnT between nad1 and trnG (Figure 2B; Figure 5A). The gene arrangement, $\operatorname{cox} 3-\operatorname{trn} A$, which is present in Po. asiatica, the Haematopinus pig lice and the human lice, is apparently ancestral to these lice. In Po. spinulosa, however, $\operatorname{trn} A$ has been inserted downstream nad6 gene (Figure 2B; Figure 4).

Translocation of tRNA genes between minichromosomes also occurred in Po. asiatica. The gene arrangement, trnP-cox3, which is present in Po. spinulosa and the Haematopinus pig lice, is apparently ancestral to the rat lice, the pig lice and the human lice (Figure 4). In Po. asiatica, however, trnP has been inserted downstream $\operatorname{trnN}$, leaving a 57-bp pseudo-trnP between nad4L and cox3 (Figure 2A; Figure 5B). Unusually, there is a 189-bp noncoding region in between $\operatorname{trn} N$ and $\operatorname{trn} P$ (Figure 2A). The gene arrangement, nad5-trnF, which is ancestral to insects [12], is retained in Po. spinulosa and the Haematopinus pig lice. In Po. asiatica, however, $\operatorname{trnF}$ has been inserted downstream nad4 gene (Figure 2A; Figure 4).

The rat louse, Po. asiatica, and the Haematopinus pig lice retained an ancestral gene arrangement of insects, cox1-trn $L_{2}$ (Figure 4) [12]. The gene arrangement, $t r n L_{1}-r r n L$, which is present in Po. asiatica, the Haematopinus pig lice, and the human head and body lice, is apparently ancestral to these lice. In Po. spinulosa, however, these two trnL genes swapped their positions: $\operatorname{trn}_{1}$ lies downstream $\operatorname{cox} 1$ in one minichromosome whereas $t r n L_{2}$ lies upstream $r r n L$ in another minichromosome (Figure 2B). Given the high sequence similarity between $\operatorname{trn}_{1}$ and $\operatorname{trn} L_{2}$ (Figure 6A; also see below), it is more likely that these two tRNA genes swapped their identities by recombination or point mutations at the third anti-codon positions than by translocations of these two genes between minichromosomes, as observed previously in the human head louse and body louse [11].
(A)

Ps trnT

Ps trnT
Pseudo-trnT

(B)

Pa trnP

Pa pseudo-trnP

(68 bp, $49 \%$ similarity)

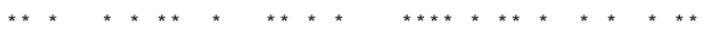

AGTCCT CACA GT CTTTGAT GACT GAGAGTTTGTACCTCTCAA GAGGTTTAGCCT GAGG- -ACTA- - - 62

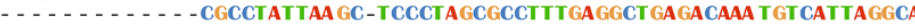

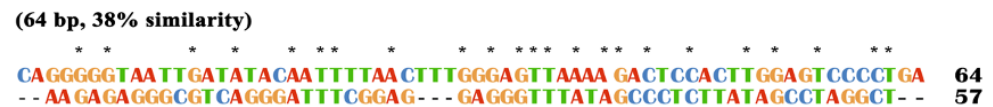

Figure 5 Alignment of the nucleotide sequences between trnT and pseudo-trnT of Polyplax spinulosa (A) and between trnP and pseudo-trnP of Polyplax asiatica (B). 


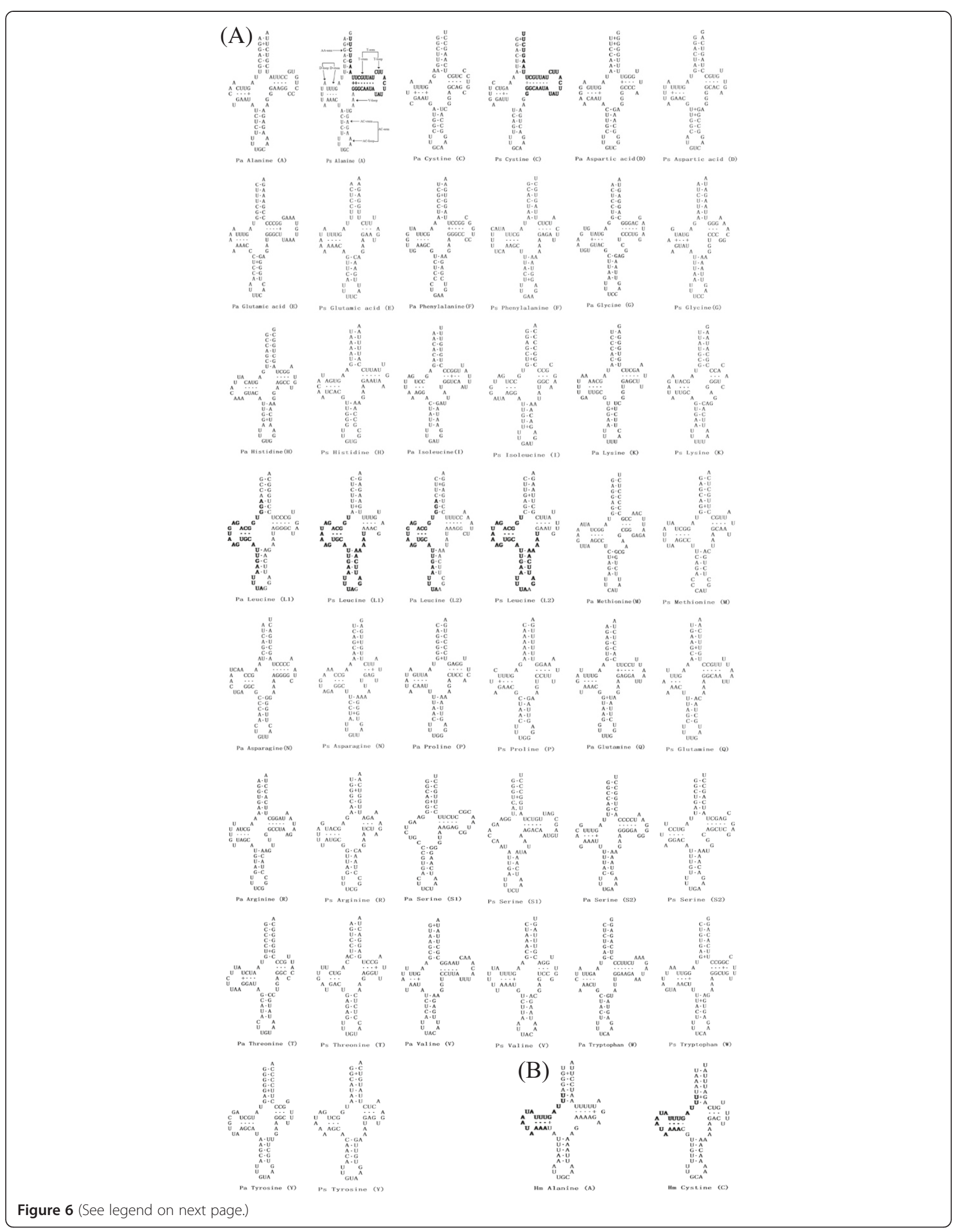


(See figure on previous page.)

Figure 6 Inferred secondary structures of the mitochondrial tRNAs of Polyplax asiatica (Pa) and Polyplax spinulosa (Ps) (A) and mitochondrial tRNAs for alanine and cysteine of the wallaby louse, Heterodoxus macropus (B). Identical sequences shared between the two tRNAs for leucine are in bold, so are the identical sequences shared between tRNA-alanine and tRNA-cystine (see also Table 2). The 17-bp identical sequences shared between the two tRNAs of Heterodoxus macropus are in bold (see also Table 2).

Recombination between $\mathrm{mt}$ genes in parasitic lice

In the human lice and the pig lice, ten pairs of $\mathrm{mt}$ genes share stretches of identical sequences much longer than expected by chance, providing striking evidence for DNA recombination between $\mathrm{mt}$ genes and between minichromosomes [10-12]. As in the human lice and the pig lice, $\operatorname{trn} L_{1}$ and $\operatorname{trn} L_{2}$ in both rat lice, Po. asiatica and Po. spinulosa, share 28-bp and 25-bp identical sequences respectively (plus a 11-bp identical sequence immediately downstream with $1 \mathrm{bp}$ in between in both species), which are 4-5 times longer than in the animals that have the typical $\mathrm{mt}$ genome organization (Table 2; Figure 6A). Recombination between $\operatorname{trn} L_{1}$ and $\operatorname{trn} L_{2}$ appears to be common in the blood-sucking lice and occurs likely more frequent than other $\mathrm{mt}$ genes.

Two other pairs of $\mathrm{mt}$ genes in the rat louse, Po. spinulosa, also share identical sequences, 36 bp between $c o b$ and $n a d 5$, and 32 bp between $\operatorname{trn} A$ and $\operatorname{trn} C$, which are 3-5 times longer than in other animals (Table 2). Recombination between $c o b$ and nad5, and between $\operatorname{trn} A$ and $\operatorname{trn} C$ in Po. spinulosa, appears to be recent evolutionary events and less common as these two pairs of genes do not share longer-than-expected sequences in the other rat louse, Po. asiatica, nor in the human lice and the pig lice (Table 2). Intriguingly, $\operatorname{trn} A$ and $\operatorname{trn} C$ of the wallaby louse, Heterodoxus macropus, share $17 \mathrm{bp}$ identical sequence (Figure 6B; Table 2), which is $2-3$ times longer than expected by chance, indicating that recombination between $\mathrm{mt}$ genes may also occur in the animals that have the typical $\mathrm{mt}$ genome organization although it is much rarer than in the blood-sucking lice, which have fragmented mt genomes.

It was suggested that recombination between tRNA genes could affect the secondary structure of their corresponding tRNAs [11]. This is, indeed, the case for tRNA-Alanine and tRNA-Cystine in the rat lice. The 32-bp identical sequence shared between $\operatorname{trn} A$ and $\operatorname{trn} C$ in $P$. spinulosa falls on the AA-arm and T-arm of tRNA-Alanine and tRNA-Cystine. These two tRNAs have the longest T-arms among all of the tRNAs of Po. spinulosa, with 8 pairs and 7 pairs respectively at the T-stems and $9 \mathrm{nt}$ at the T-loop, in comparison to the average 4.2 pairs and $4.6 \mathrm{nt}$ of the 22 tRNAs (Table 3; Figure 6A). In contrast, in the other rat louse, Po. asiatica, in which $\operatorname{trn} A$ and $\operatorname{trn} C$ do not share longer-than-expected sequences, the T-arms of tRNA-Alanine and tRNA-Cystine

Table 2 The longest stretches of identical sequence shared by mitochondrial genes in two rat lice, three human lice, two pig lice, which have fragmented mitochondrial genomes, and six other species of bilateral animals that have the typical mitochondrial genomes

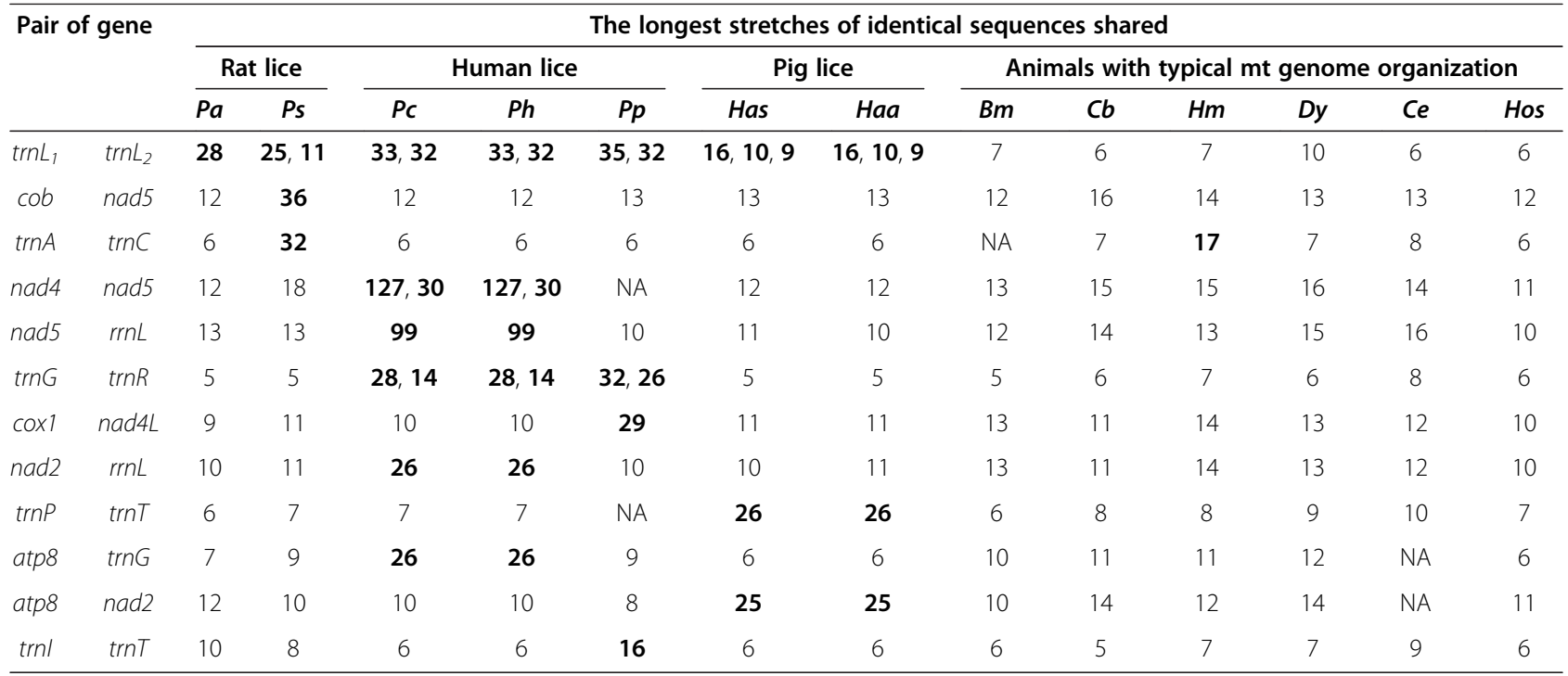

Note: Abbreviations of species names are: Pa, Polyplax asiatica (louse of the greater bandicoot rat); Ps, Polyplax spinulosa (louse of the Asian house rat); Pc, Pediculus capititis (human head louse); Ph, (human body louse); Pp, Pthirus pubis (human pubic louse); Has, Haematopinus suis (domestic pig louse); Haa, Haematopinus apri (wild pig louse); Bm, Bothriometopus macrocnemis (screamer louse); Cb, Campanulotes bidentatus (pigeon louse); Hm, Heterodoxus macropus (wallaby louse); Dy, Drosophila yakuba (fruitfly); $\mathrm{Ce}$, Caenorhabditis elegans (roundworm); Hos, Homo sapiens (human); NA, not available. Stretches of shared identical sequences longer than expected by chance are in bold. 
Table 3 Length of T-stem, T-loop and T-arm of the mitochondrial tRNAs of the rat lice, Polyplax asiatica (Pa) and Polyplax spinulosa (Ps)

\begin{tabular}{|c|c|c|c|c|c|c|c|}
\hline tRNA & Anti-codon & $\mathrm{Pa}$ T-stem (pairs) & Ps T-stem (pairs) & Pa T-loop (nt) & Ps T-loop (nt) & PaT-arm (nt) & Ps T-arm (nt) \\
\hline Alanine (A) & UGC & 5 & 8 & 7 & 9 & 17 & 25 \\
\hline Cystine (C) & GCA & 4 & 7 & 5 & 9 & 13 & 23 \\
\hline Aspartic acid (D) & GUC & 4 & 4 & 3 & 4 & 11 & 12 \\
\hline Glutamic acid (E) & UUC & 5 & 3 & 11 & 4 & 21 & 10 \\
\hline Phenylalanine (F) & GAA & 5 & 4 & 6 & 4 & 16 & 12 \\
\hline Glycine (G) & UCC & 5 & 3 & 5 & 6 & 15 & 12 \\
\hline Histidine $(H)$ & GUG & 4 & 5 & 4 & 3 & 12 & 13 \\
\hline Isoleucine (I) & GAU & 5 & 3 & 6 & 4 & 16 & 10 \\
\hline Lysine (K) & UUU & 5 & 3 & 3 & 3 & 13 & 9 \\
\hline Leucine $\left(L_{1}\right)$ & UAG & 5 & 4 & 4 & 3 & 14 & 11 \\
\hline Leucine $\left(\mathrm{L}_{2}\right)$ & UAA & 5 & 4 & 6 & 4 & 16 & 12 \\
\hline Methionine (M) & CAU & 3 & 4 & 10 & 3 & 16 & 11 \\
\hline Asparagine $(\mathrm{N})$ & GUU & 5 & 3 & 4 & 3 & 14 & 9 \\
\hline Proline (P) & UGG & 4 & 4 & 4 & 3 & 12 & 11 \\
\hline Glutamine $(\mathrm{Q})$ & UUG & 5 & 5 & 6 & 6 & 16 & 16 \\
\hline Arginine (R) & UCG & 5 & 3 & 6 & 4 & 16 & 10 \\
\hline Serine $\left(S_{1}\right)$ & UCU & 5 & 5 & 8 & 10 & 18 & 20 \\
\hline Serine $\left(S_{2}\right)$ & UGA & 5 & 5 & 6 & 4 & 16 & 14 \\
\hline Threonine $(T)$ & UGU & 3 & 4 & 5 & 3 & 11 & 11 \\
\hline Valine $(V)$ & UAC & 5 & 3 & 9 & 4 & 19 & 10 \\
\hline Tryptophan (W) & UCA & 6 & 5 & 8 & 4 & 20 & 14 \\
\hline Tyrosine $(Y)$ & GUA & 3 & 3 & 4 & 4 & 10 & 10 \\
\hline Total & & 101 & 92 & 130 & 101 & 332 & 285 \\
\hline Mean & & 4.6 & 4.2 & 5.9 & 4.6 & 15.1 & 13.0 \\
\hline
\end{tabular}

have 5 pairs and 4 pairs respectively at the T-stems, and $7 \mathrm{nt}$ and $5 \mathrm{nt}$ at the T-loop, which are very close to the average 4.6 pairs and 5.9 nt of the 22 tRNAs (Table 3).

\section{A possible link between the extent of $\mathrm{mt}$ genome} fragmentation and the length of life cycle

The rat lice in the genus Polyplax share their MRCA with the human lice $47 \mathrm{Mya}$, and share their MRCA with the pig lice $\sim 67$ Mya (Figure 4) [3]. The mt genomes of the two Polyplax species we sequenced in the present study have 3.4 genes on average on each minichromosome and thus, are less fragmented than those of the human lice (2.1 and 2.4 genes per minichromosome) but are more fragmented than those of the pig lice (4.1 genes per minichromosome). Clearly, the extent of mitochondrial genome fragmentation varies among different lineages of the blood-sucking lice.

The pig lice, Haematopinus suis and Haematopinus apri, have the least fragmented mt genomes among the blood-sucking lice whose mt genomes have been sequenced completely or near completely sequenced to date [12]. Intriguingly, these two Haematopinus species have the

Table 4 Body length, life-cycle length and number of mitochondrial genes per minichromosome of five species of blood-sucking lice

\begin{tabular}{|c|c|c|c|c|c|}
\hline Species of lice & $\begin{array}{c}\text { Pig louse } \\
\text { Haematopinus suis }\end{array}$ & $\begin{array}{c}\text { Rat louse } \\
\text { Polyplax spinulosa }\end{array}$ & $\begin{array}{c}\text { Human pubic louse } \\
\text { Pthirus pubis }\end{array}$ & $\begin{array}{l}\text { Human body louse } \\
\text { Pediculus humanus }\end{array}$ & $\begin{array}{c}\text { Human head louse } \\
\text { Pediculus capitis }\end{array}$ \\
\hline Adult body length (mm) & $4-6$ & $0.6-1.5$ & $1.3-2.0$ & $2.3-3.6$ & $2.1-3.3$ \\
\hline Length of life cycle (days) & $29-48$ & $25-28$ & $16-25$ & $14-20$ & $13-17$ \\
\hline $\begin{array}{l}\text { Mitochondrial genes per } \\
\text { minichromosome }\end{array}$ & 4.1 & 3.4 & 2.4 & 2.1 & 2.1 \\
\hline
\end{tabular}

Note: The information of body length and life cycle was from Dynum et al. [31], Florence [32], Wall and Shearer [30] and Baker et al. [33] for the pig louse; from Baker [22] and Goodwin et al. [34] for the rat louse; from Buxton [35] and Service [36] for the human pubic louse; and from Buxton [35], Buxton [37] and Service [36] for the human body louse and head louse. 
largest body size (up to $6 \mathrm{~mm}$ long) among the bloodsucking lice known [30]. The body size of the bloodsucking lice, however, does not appear to be linked to the extent of $\mathrm{mt}$ genome fragmentation as the human lice, Pediculus humanus and Pediculus capitis, have larger body size (up to $3.6 \mathrm{~mm}$ long) than the Polyplax rat lice (up to $1.5 \mathrm{~mm}$ long) but have more fragmented $\mathrm{mt}$ genomes than the Polyplax rat lice (Table 4).

Instead, the length of life cycle of the blood-sucking lice appears to be linked to the extent of $\mathrm{mt}$ genome fragmentation. The pig louse, H. suis, has the longest life cycle (29-48 days depending on weather; no data available to $H$. apri) and the least fragmented $\mathrm{mt}$ genome among the blood-sucking lice whose $\mathrm{mt}$ genomes have been sequenced completely or near completely to date (Table 4). In contrast, the human head louse, Pe. capitis, and the body louse, Pe. humanus, have the shortest life cycle (13-20 days) and the most fragmented $\mathrm{mt}$ genomes. The rat louse, Po. spinulosa, has both the length of life cycle (25-28 days; no data available to Po. asiatica) and the extent of mt genome fragmentation in between the pig lice and the human head and body lice. Furthermore, the human pubic louse, Pt. pubis, has both the length of life cycle (16-25 days) and the extent of $\mathrm{mt}$ genome fragmentation in between the rat lice and the human head and body lice. The inverse link between the length of life cycle and the extent of $\mathrm{mt}$ genome fragmentation, indicated in the present study by limited number of species, can be tested further with data from more species of blood-sucking lice, and other eukaryotes that have fragmented $\mathrm{mt}$ genomes such as the ichthyosporean protists [16], diplonemid protists [17] and box jellyfish [18]. Currently, there is no sufficient data and information, to our knowledge, to link the length of life cycle (or other lifehistory factors) with the extent of mt genome fragmentation in these eukaryotes. Theoretically, if mitochondrial genome fragmentation was a continuous process and each generation contributed approximately equally towards fragmentation, then it would be expected that the extent of fragmentation be inversely linked to the length of life cycle.

\section{Conclusions}

We sequenced the mt genomes of Po. asiatica and Po. spinulosa, collected from the greater bandicoot rat, $B$. indica, and the Asian house rat, $R$. tanezumi. We identified all of the $37 \mathrm{mt}$ genes common to animals in these rat lice. The mt genes of Po. asiatica and Po. spinulosa are on 11 minichromosomes; each minichromosome is $2-4 \mathrm{~kb}$ long and has $2-7$ genes. The two rat lice share the same pattern for the distribution of the protein-coding genes and rRNA genes over the minichromosomes, but differ in the pattern for the distribution of 8 of the 22 tRNA genes. The mt genomes of the two Polyplax rat lice have 3.4 genes, on average, on each minichromosome and thus, are less fragmented than those of the human lice
(2.1 and 2.4 genes per minichromosome) but are more fragmented than those of the pig lice (4.1 genes per minichromosome). Our results revealed distinct patterns of $\mathrm{mt}$ genome fragmentation between the two Polyplax species of rat lice. We also showed that the extent of $\mathrm{mt}$ genome fragmentation appears to have an inverse link with the length of life cycle of the rat lice, the human lice and the pig lice. Whether, or not, the extent of $\mathrm{mt}$ genome fragmentation is indeed linked to the length of life cycle, however, needs to be tested further with data from more species and broader phylogenetic ranges of blood-sucking lice, and other eukaryotes that have fragmented $\mathrm{mt}$ genomes.

\section{Availability of supporting data}

The nucleotide sequences of the mt genomes of the rat lice supporting the results of this article have been deposited in GenBank [accession numbers KF647751-KF647772; http://www.ncbi.nlm.nih.gov/].

\section{Additional files}

\section{Additional file 1: PCR primers used to amplify and sequence the mitochondrial genomes of the rat lice, Polyplax asiatica $(\mathrm{Pa})$ and} Polyplax spinulosa (Ps).

Additional file 2: PCR primers used to verify the mitochondrial minichromosomes of the rat lice, Polyplax asiatica and Polyplax spinulosa.

Additional file 3: Alignment of nucleotide sequences of parts of the non-coding regions upstream (A) and downstream (B) of the coding regions of the 11 mitochondrial minichromosomes of Polyplax asiatica, the louse of the greater bandicoot rat, Bandicota indica. $57 \mathrm{~F}$ and $57 \mathrm{R}$ are the primers used to amplify the coding regions of all mitochondrial minichromosomes of Polyplax asiatica.

Additional file 4: Alignment of nucleotide sequences of parts of the non-coding regions upstream $(A)$ and downstream $(B)$ of the coding regions of the 11 mitochondrial minichromosomes of Polyplax spinulosa, the louse of the Asian house rat, Rattus tanezumi. 301F and $301 R$ are the primers used to amplify the coding regions of all mitochondrial minichromosomes of Polyplax spinulosa.

\section{Abbreviations}

$\mu$ : Microliter; atp6 and atp8: Genes for ATP synthase subunits 6 and 8; bp: Base pair; cob: Gene for cytochrome b; $\operatorname{cox} 1 \operatorname{cox} 2$ and $\operatorname{cox} 3$ : Genes for cytochrome coxidase subunits 1, 2 and 3; DNA: Deoxyribonucleic acid; kb: Kilo base pair; min: Minute; MRCA: Most recent common ancestor; Mt: Mitochondrial; Mya: Million years ago; nad1, nad2, nad3, nad4, nad4L, nad5 and nad6: Mitochondrial genes for NADH dehydrogenase subunits 1-6 and 4 L; PCR: Polymerase chain reaction; RNA: Ribonucleic acid;

rRNA: Ribosomal RNA; rrnS and rrnL: Genes for small and large subunits of ribosomal RNA; sec: Second; T: Thymine; tRNA: transfer RNA; tRNA: transfer RNA; $\operatorname{trn} A$ or $A$ : tRNA gene for alanine; $\operatorname{trn} C$ or $C$ : tRNA gene for cysteine; $\operatorname{trn} D$ or D: tRNA gene for aspartic acid; trnE or E: tRNA gene for glutamic acid; trnF or F: tRNA gene for phenylalanine; trnG or G: tRNA gene for glycine; trnH or $H$ : tRNA gene for histidine; trnl or l: tRNA gene for isoleucine; trnK or $K$ : tRNA gene for lysine; $\operatorname{trn} L_{1}$ or $L_{1}$ : tRNA gene for leucine (anticodon NAG); $t r n L_{2}$ or $L_{2}$ : tRNA gene for leucine (anticodon YAA); trnM or M: tRNA gene for methionine; $\operatorname{trnN}$ or $N$ : tRNA gene for asparagine; $\operatorname{trn} P$ or $P$ : tRNA gene for proline; trn $Q$ or $Q$ : tRNA gene for glutamine; $\operatorname{trn} R$ or $R$ : tRNA gene for arginine; $t r n S_{1}$ or $S_{1}$ : tRNA gene for serine (anticodon NCU); trnS $S_{2}$ or $S_{2}$ : tRNA gene for serine (anticodon NGA); trnT or T: tRNA gene for threonine; trnV or $V$ : tRNA gene for valine; trnW or W: tRNA gene for tryptophan; trnY or $Y$ : tRNA gene for tyrosine; U: Uracil. 


\section{Competing interests}

The authors declare that they have no competing interests.

\section{Authors' contributions}

WGD, SS, DCJ, XGG and RS designed the research. WGD, SS and RS performed the research. DCJ, XGG and RS contributed reagents and materials. WGD, SS and RS analyzed the data. WGD and RS wrote the manuscript. All authors have read and approved the final manuscript.

\section{Acknowledgments}

We thank the anonymous reviewers for comments that have greatly improved this manuscript. We acknowledge funding support from The Program for Innovative Research Team in Guizhou ([2009]4003 to DCJ), Natural Science Foundation of China (81260259 to XGG), the Australian Research Council (DP120100240 to RS), and Australia-China Science \& Research Fund (ACSRF00980 to RS).

\section{Author details}

'Institute of Entomology, Guizhou University, and the Provincial Key Laboratory for Agricultural Pest Management in Mountainous Region, Guiyang 550025, China. ${ }^{2}$ Institute of Pathogens and Vectors, Dali University, and the Key Laboratory for Preventing and Controlling Plague in Yunnan Province, Dali 671000, China. ${ }^{3}$ GeneCology Research Centre, Faculty of Science, Health, Education and Engineering, University of the Sunshine Coast, Maroochydore, Queensland 4556, Australia.

Received: 20 September 2013 Accepted: 15 January 2014 Published: 18 January 2014

\section{References}

1. Kim KC: Evolution and host associations of Anoplura. In Coevolution of Parasitic Arthropods and Mammals. Edited by Kim KC. New York: John Wiley and Sons Press; 1985:197-231.

2. Lehane MJ: The Biology of the Blood Sucking Insects. 2nd edition. New York: Cambridge University Press; 2005.

3. Light JE, Smith VS, Allen JM, Durden LA, Reed RL: Evolutionary history of mammalian sucking lice (Phthiratpera: Anoplura). BMC Evol Biol 2010, 10:292.

4. Kim KC, Ludwig HW: The family classification of the Anoplura. Syst Entomol 1978, 3:249-284.

5. Kim KC: Evolutionary parallelism in Anoplura and eutherian mammals. In Biosystematics of Haematophagous Insects. 37th edition. Edited by Service MW. Oxford: Oxford University Press; 1988:91-114.

6. Durden LA, Musser GG: The sucking lice (Insecta, Anoplura) of the world: a taxonomic checklist with records of mammalian hosts and geographical distributions. Bull Amer Mus Nat Hist 1994, 218:1-90.

7. Durden LA, Musser GG: The mammalian hosts of the sucking lice (Anoplura) of the world: a host-parasite list. Bull Soc Vector Ecol 1994, 19:130-168.

8. Boore JL: Animal mitochondrial genomes. Nucleic Acids Res 1999, 27:1767-1780.

9. Lavrov DV: Key transitions in animal evolution: a mitochondrial DNA perspective. Integr Comp Biol 2007, 47:734-743.

10. Shao R, Kirkness EF, Barker SC: The single mitochondrial chromosome typical of animals has evolved into 18 minichromosomes in the human body louse, Pediculus humanus. Genome Res 2009, 19:904-912.

11. Shao R, Zhu XQ, Barker SC, Herd K: Evolution of extensively fragmented mitochondrial genomes in the lice of humans. Genome Biol Evol 2012, 4:1088-1101.

12. Jiang HW, Barker SC, Shao R: Substantial variation in the extent of mitochondrial genome fragmentation among blood-sucking lice of mammals. Genome Biol Evol 2013, 5:1298-1308.

13. Suga K, Welch DBM, Tanaka Y, Sakakura Y, Hagiwarak A: Two circular chromosomes of unequal copy number make up the mitochondrial genome of the rotifer Brachionus plicatilis. Mol Biol Evol 2008, 25:1129-1137.

14. Wei DD, Shao R, Yuan ML, Dou W, Barker SC, Wang JJ: The multipartite mitochondrial genome of Liposcelis bostrychoophila: insights into the evolution of mitochondrial genomes in bilateral animals. PLoS One 2012 7:e33973.
15. Gibson T, Blok VC, Dowton M: Sequence and characterization of six mitochondrial subgenomes from Globodera rostochiensis: Multipartite structure is conserved among close nematode relatives. J Mol Evol 2007 65:308-315.

16. Burger G, Forget L, Zhu Y, Gray MW, Lang BF: Unique mitochondrial genome architecture in unicellular relatives of animals. Proc Natl Acad Sci U S A 2003, 100:892-897.

17. Marande W, Lukes J, Burger G: Unique mitochondrial genome structure in diplonemids, the sister group of kinetoplastids. Eukaryot Cell 2005, 4:1137-1146.

18. Smith DR, Kayal E, Yanagihara AA, Collins AG, Pirro S, Keeling PJ: First complete mitochondrial genome sequence from a box jellyfish reveals a highly fragmented linear architecture and insights into telomere evolution. Genome Biol Evol 2012, 4:52-58.

19. Chin TH: Taxonomy and fauna of sucking lice (Anoplura) in China. Beijing: Science Press; 1999:1-132.

20. Crystal MM: The mechanism of transmission of Haemobartonella muris (Mayer) of rats by the spined rat louse, Polyplax spinulosa (Burmeister). J Parasitol 1958, 44:603-606.

21. Neimark H, Johansson KE, Rikihisa Y, Tully JG: Revision of haemotrophic Mycoplasma species names. Int J Syst Evol Microbiol 2002, 52:683.

22. Baker DG: Parasitic diseases. In The Laboratory Rat. Secondth edition. Edited by Suckow MA, Weisbroth SH, Franklin CL. Elsevier Press A Volume in American College of Laboratory Animal Medicine:; 2006:453-478.

23. Kearse M, Moir R, Wilson A, et al: (11 co-authors): Geneious basic: An integrated and extendable desktop software platform for the organization and analysis of sequence data. Bioinformatics 2012, 28:1647-1649.

24. Lowe TM, Eddy SR: tRNAscan-SE: a program for improved detection of transfer RNA genes in genomic sequence. Nucleic Acids Res 1997, 25:955-964.

25. Laslett D, Canback B: ARWEN: a program to detect tRNA genes in metazoan mitochondrial nucleotide sequences. Bioinformatics 2008, 24:172-175.

26. Altschul SF, Madden TL, Schaffer AA, Zhang J, Zhang Z, Miller W, Lipman DJ: Gapped BLAST and PSI-BLAST: a new generation of protein database search programs. Nucleic Acids Res 1997, 25:3389-3402.

27. Gish W, States DJ: Identification of protein coding regions by database similarity search. Nature Genet 1993, 3:266-272.

28. Rice P, Longden I, Bleasby A: EMBOSS: The European molecular biology open software suite. Trends Genet 2000, 16:276-277.

29. Larkin MA, et al: Clustal $W$ and Clustal $X$ version 2.0. Bioinformatics 2007, 23:2947-2948.

30. Wall R, Shearer D: Veterinary Ectoparasites: Biology, Pathology and Control. Secondth edition. Wiley-Blackwell Press; 2001.

31. Dynum E, Ward C, Meeks D: Hog louse, Haematopinus suis, population growth and distribution on its host. Southwest Entomol 1978, 3:106-112.

32. Florence L: The hog louse, Haematopinus suis Linné: its biology, anatomy and histology. Cornell University Agric Exp Station Mem 1921, 51:635-743.

33. Baker JR, Apperson CS, Arends JJ: Insect and related pests of man and animals. The North Carolina Agric Ext Serv 2013. http://ipm.ncsu.edu/AG369/.

34. Goodin BS, Yarbrough LW, Head KL: Rats and Mice: Parasitic Diseases. University of Washington Health Sciences Center for Educational Resources and the American College of Laboratory Animal Medicine; 2000.

35. Buxton PA: The louse, an account of the lice which infest man, their medical importance and control. 2nd edition. London: Edward Arnold Press; 1947.

36. Service M: Medical Entomology for Students. 5th edition. New York: Cambridge University Press; 2012.

37. Buxton PA: The louse: Present knowledge and future work. Trans $R$ Soc Trop Med Hyg 1940, 33:365-379.

doi:10.1186/1471-2164-15-44

Cite this article as: Dong et al:: Fragmented mitochondrial genomes of the rat lice, Polyplax asiatica and Polyplax spinulosa: intra-genus variation in fragmentation pattern and a possible link between the extent of fragmentation and the length of life cycle. BMC Genomics 2014 15:44. 